\title{
Palladium(II)-catalyzed oxidation of tranexamic acid by bromamine-B in alkaline medium and uncatalyzed reaction in acid medium: A study of kinetic and mechanistic chemistry
}

\author{
Puttaswamy*, Anu Sukhdev, J.P. Shubha \\ Department of Post-Graduate Studies in Chemistry, Bangalore University, Central College Campus, Bangalore 560 001, India
}

\section{A R T I C L E I N F O}

\section{Article history:}

Received 19 May 2010

Received in revised form 3 September 2010

Accepted 3 September 2010

Available online 21 September 2010

\section{Keywords:}

Pd(II) catalysis

Tranexamic acid

Bromamine-B

Oxidation-kinetics

\begin{abstract}
A B S T R A C T
Tranexamic acid (TA) possess antifibrinolytic properties and finds extensive applications in pharmaceuticals. Its oxidation-kinetic study is of much significance in understanding the mechanistic profile of TA in biological systems. In this context, a systematic kinetic study of palladium(II) (Pd(II)) catalyzed oxidation of TA by sodium $\mathrm{N}$-bromobenzenesulfonamide or bromamine-B (BAB) in alkaline medium and uncatalyzed reaction in perchloric acid medium at $303 \mathrm{~K}$ was investigated. In acid medium, the reaction exhibits a first-order dependence of rate on $[\mathrm{BAB}]_{\mathrm{o}}$ and less than unity order dependence on $[\mathrm{TA}]_{\mathrm{o}}$. The reaction rate shows inverse less than unity order dependence with respect to $\left[\mathrm{H}^{+}\right]$. In alkaline medium, the reaction shows first-order dependence on both $[\mathrm{BAB}]_{\mathrm{o}}$ and $[\mathrm{Pd}(\mathrm{II})]$ and zero-order with respect to $[\mathrm{TA}]_{0}$. The order with respect to $\left[\mathrm{OH}^{-}\right]$is less than unity. Activation parameters have been evaluated. The oxidation reactions are nearly 10 -fold faster in acid medium in comparison with alkaline medium. In alkaline medium, the $\mathrm{Pd}(\mathrm{II})$ catalyzed reactions are about 6 -fold faster than the uncatalyzed reaction. Further, the catalytic constant $\left(K_{C}\right)$ has been calculated at different temperatures and activation parameters with respect to $\mathrm{Pd}(\mathrm{II})$ catalyst have also been evaluated. The conjugate acid $\mathrm{C}_{6} \mathrm{H}_{5} \mathrm{SO}_{2} \mathrm{NHBr}$ and the anion $\mathrm{C}_{6} \mathrm{H}_{5} \mathrm{SO}_{2} \mathrm{~N}^{-} \mathrm{Br}$ of $\mathrm{BAB}$ have been postulated as the reactive oxidizing species in acid and alkaline media, respectively. The proposed mechanisms and derived rate laws are in agreement with the observed kinetics.
\end{abstract}

(C) 2010 Elsevier B.V. All rights reserved.

\section{Introduction}

The diverse nature of the chemistry of N-metallo-N-haloarylsulfonamides, generally known as organic $\mathrm{N}$-haloamines, is due to their ability to act as sources of halonium cations, hypohalite species and $\mathrm{N}$-anions [1]. Chloramine-T (CAT) and chloramine$B(C A B)$ are the prominent members of organic haloamines and their chemistry has been well documented [1-6]. Bromamine- $\mathrm{B}$ $\left(\mathrm{C}_{6} \mathrm{H}_{5} \mathrm{SO}_{2} \mathrm{NBrNa} 1.5 \mathrm{H}_{2} \mathrm{O}\right.$; $\left.\mathrm{BAB}\right)$, the bromine analogue of $\mathrm{CAB}$, is found to be a better oxidizing agent than its chloro compound. Although BAB is a better oxidant, not much attention has been focussed particularly on the kinetic and mechanistic aspects of oxidation of pharmaceuticals with this reagent [7-9].

Tranexamic acid (trans-4-(aminomethyl)cyclohexane carboxylic acid; TA) is a antifibrinolytic drug. The hemostatic properties of this drug mainly relate to its ability to inhibit the activation of plasminogen to plasmin thereby preventing excess loss of blood in hyperfibrinolytic conditions [10]. It is used for bleeding

\footnotetext{
* Corresponding author. Tel.: +91 080 22961340; fax: +91080 22964331.

E-mail address: pswamy_chem@yahoo.com ( Puttaswamy).
}

or risk of bleeding upon increased fibrinolysis in cases such as malignant neoplasms, post operational bleeding, gastro-intestinal bleeding and hematuria [11,12]. Recently, it gained attention as skin-whitening agent due to its inhibitory effect on UV-induced pigmentation in vivo [13]. To the best of our knowledge, there is no report available in the literature with regard to the kinetics of oxidation of this drug by any oxidant from the stand point of its mechanistic aspects. The oxidation-kinetic study is of much benefit in understanding the mechanistic profile of TA in acidic and alkaline media, so that the study could throw some light on the mechanism of metabolic conversion of TA in biological systems. Consequently, the present kinetic study gives an impetus, as the substrate TA is a potent drug.

Catalysis by platinum metal ions, plays a vital role in understanding the mechanistic chemistry of a particular redox reaction. The use of platinum metal ions as catalysts in redox reactions has become important due to their strong catalytic influence in many chemical processes such as oxidation, reduction, carboxylation, halogenation and hydrogenation reactions $[14,15]$. Kinetic studies of redox reactions using such metal ions may reveal mechanistic details of the reactions which are advantageously used in the interpretation of these reactions. From the literature survey, 
it is evident that a lot of attention has been paid on the role of palladium(II)chloride $(\mathrm{Pd}(\mathrm{II}))$ catalyst in a number of redox reactions, particularly in alkaline medium, but negligible attention has been paid on the use of $\mathrm{Pd}(\mathrm{II})$ as a homogenous catalyst for the oxidation of pharmaceuticals. This give us an impulse to investigate the present redox system in alkaline medium in the presence of $\mathrm{Pd}(\mathrm{II})$ catalyst in order to delineate the interaction and mechanism of Pd(II) with TA and BAB.

During preliminary investigations, TA-BAB oxidation reactions were found to be facile in $\mathrm{HClO}_{4}$ medium but were become very sluggish in alkaline medium. Alternatively, we found that $\mathrm{Pd}(\mathrm{II})$ catalyst even at trace concentrations (ca. $6.0 \times 10^{-6} \mathrm{~mol} \mathrm{dm}^{-3}$ ) can potentially catalyze the TA-BAB redox reactions in alkaline medium and the rate becomes measurable by titrimetric method. Consequently, in the present communication, we report for the first time the results of the detailed investigations on the kinetic and mechanistic aspects of TA-BAB reaction in $\mathrm{HClO}_{4}$ medium and also in alkaline medium catalyzed by $\mathrm{Pd}(\mathrm{II})$. This research programme is designed through oxidation-kinetic studies with the following objectives: (i) to accumulate kinetic data, (ii) to formulate elegant schemes, (iii) to design rigorous kinetic models, (iv) to deduce the thermodynamic parameters, (v) to ascertain the various reactive species, (vi) to characterize the oxidation products, (vii) to explore the role and catalytic efficiency of Pd(II) catalyst in alkaline medium and (viii) to correlate the reactivity of the present redox system in acid and alkaline media. grade chemicals and doubly distilled water were used throughout the work.

\subsection{Kinetic measurement}

Kinetic runs were performed under pseudo first-order conditions with a known excess of TA over BAB at $303 \mathrm{~K}$. The kinetic procedure followed is similar to that reported earlier [9]. The course of the reaction was studied more than two half-lives. The pseudo first-order rate constants $\left(k^{\prime} \mathrm{s}^{-1}\right)$, calculated from the linear plots of $\log [\mathrm{BAB}]$ versus time, were reproducible within $\pm 5 \%$. Regression coefficient $(r)$ of the experimental data was carried out on an fx-100W statistical calculator.

\subsection{Reaction stoichiometry}

The reaction mixtures containing different concentrations of $\mathrm{BAB}$ and $\mathrm{TA}$ in $4.0 \times 10^{-3} \mathrm{~mol} \mathrm{dm}^{-3} \quad \mathrm{HClO}_{4} / \mathrm{NaOH}$ $\left(6.0 \times 10^{-6} \mathrm{~mol} \mathrm{dm}^{-3} \mathrm{Pd}(\mathrm{II})\right.$ in alkaline medium) were allowed to react for $24 \mathrm{~h}$ at $303 \mathrm{~K}$. The unchanged oxidant in the reaction mixture was determined by iodometric titrations. The analysis showed that one mole of TA reacted with two moles of the oxidant in both the media. The observed stoichiometry can be represented by Eq. (1):

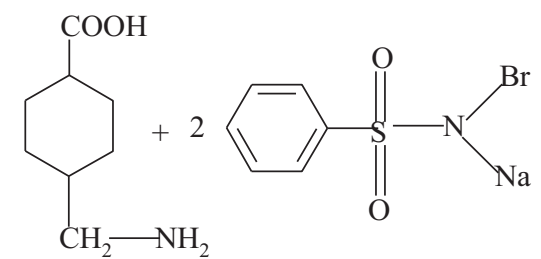

$\longrightarrow$ COOH

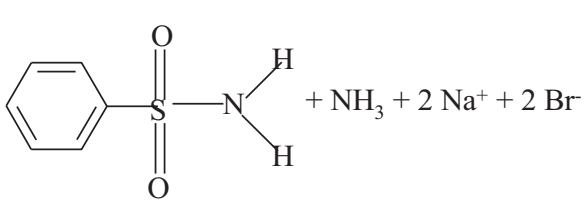

\subsection{Product characterization}

The TA-BAB reaction mixture was allowed to progress in the presence of acid and alkali separately for $24 \mathrm{~h}$ at $303 \mathrm{~K}$ under stirred condition. After completion of the reaction, the reaction products were neutralized with alkali/acid and extracted with ether. The organic products were subjected to spot tests and chromatographic analysis (TLC technique), which revealed the formation of trans-cyclohexane-1,4-dicarboxylic acid as the oxidation product of TA and benzenesulfonamide as the reduction product of BAB. These products were confirmed by GC-MS analysis. GC-MS data was obtained on a 17A Shimadzu gas chromatograph with a QP-5050A Shimadzu mass spectrometer. The mass spectrum showed a molecular ion peak at 172 amu clearly confirming transcyclohexane-1,4-dicarboxylic acid (Fig. 1).

Benzenesulfonamide $\left(\mathrm{PhSO}_{2} \mathrm{NH}_{2}\right)$, was extracted with ethyl acetate and identified [16] by TLC using petroleum ether- $\mathrm{CHCl}_{3}-1$ butanol $(2: 2: 1, v / v)$ as the solvent system and iodine as spray reagent $\left(R_{f}=0.88\right)$. Further, the molecular ion peak of $157 \mathrm{amu}$ clearly confirms benzene sulphonamide. All other peaks in GC-MS are interpreted in accordance with the observed structure. Ammonia was detected by Nessler's reagent test.

\section{Results and discussion}

Pseudo first-order conditions $\left([\mathrm{TA}]_{\mathrm{o}} \gg[\mathrm{BAB}]_{\mathrm{o}}\right)$ were maintained for all the kinetic runs in both the media. The kinetics of oxidation of TA by BAB was investigated at several initial concentrations of the reactants in acid and alkaline media. Since the kinetic and mechanistic traits are different in acid and alkaline media, for the sake of 


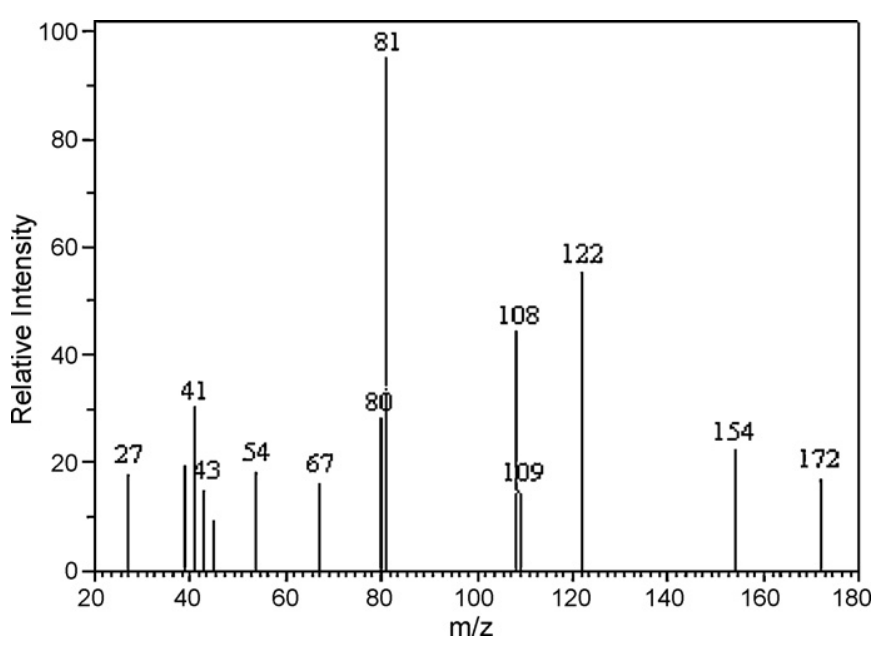

Fig. 1. Mass spectrum of trans-cyclohexane-1,4-dicarboxylic acid with its parent molecular ion peak at mass/charge 172 .

convenience the salient features obtained in these two media are discussed separately in the following.

\subsection{Kinetics of oxidation of $\mathrm{TA}$ by $\mathrm{BAB}$ in $\mathrm{HClO}_{4}$ medium}

At constant $[\mathrm{TA}]_{\mathrm{O}},\left[\mathrm{HClO}_{4}\right]$ and temperature, where $[\mathrm{TA}]_{\mathrm{O}} \gg[\mathrm{BAB}]_{\mathrm{o}}$, plots of $\log [\mathrm{BAB}]_{\mathrm{o}}$ versus time are linear $(r>0.9824)$, indicating a first-order dependence of rate on $[\mathrm{BAB}]_{0}$. The pseudo-first-order rate constants $\left(k^{\prime} \mathrm{s}^{-1}\right)$, are independent of $[\mathrm{BAB}]_{\mathrm{o}}$ (Table 1 ) confirming the first-order dependence of rate on $[\mathrm{BAB}]_{\mathrm{o}}$. The dependence of the rate on $[\mathrm{TA}]_{\mathrm{o}}$ was studied in the concentration range of $0.1 \times 10^{-3}$ to $20.0 \times 10^{-3} \mathrm{~mol} \mathrm{dm}^{-3}$ (Table 1). Values of $k^{\prime}$ increased with increase in [TA $]_{0}$ in the concentration range of $0.1 \times 10^{-3}$ to $6.0 \times 10^{-3} \mathrm{~mol} \mathrm{dm}^{-3}$. A plot

Table 1

Influence of oxidant, substrate and acid concentrations on the reaction rate at $303 \mathrm{~K}$.

\begin{tabular}{|c|c|c|c|}
\hline$[\mathrm{BAB}]_{\mathrm{o}}\left(\times 10^{4} \mathrm{~mol} \mathrm{dm}^{-3}\right)$ & $\begin{array}{l}{[\mathrm{TA}]_{\mathrm{o}}\left(\times 10^{3}\right.} \\
\left.\mathrm{mol} \mathrm{dm}^{-3}\right)\end{array}$ & $\begin{array}{l}{\left[\mathrm{HClO}_{4}\right]} \\
\left(\times 10^{3} \mathrm{~mol} \mathrm{dm}^{-3}\right)\end{array}$ & $k^{\prime}\left(\times 10^{4} \mathrm{~s}^{-1}\right)$ \\
\hline 0.5 & 1.5 & 4.0 & 7.25 \\
\hline 0.75 & 1.5 & 4.0 & 7.21 \\
\hline 1.0 & 1.5 & 4.0 & 7.30 \\
\hline 2.0 & 1.5 & 4.0 & 7.38 \\
\hline 4.0 & 1.5 & 4.0 & 7.24 \\
\hline 1.0 & 0.1 & 4.0 & 0.94 \\
\hline 1.0 & 0.2 & 4.0 & 1.96 \\
\hline 1.0 & 0.4 & 4.0 & 3.95 \\
\hline 1.0 & 0.5 & 4.0 & 4.55 \\
\hline 1.0 & 0.75 & 4.0 & 5.28 \\
\hline 1.0 & 1.5 & 4.0 & 7.31 \\
\hline 1.0 & 3.0 & 4.0 & 9.59 \\
\hline 1.0 & 6.0 & 4.0 & 12.9 \\
\hline 1.0 & 8.0 & 4.0 & 12.8 \\
\hline 1.0 & 12.0 & 4.0 & 12.9 \\
\hline 1.0 & 16.0 & 4.0 & 13.0 \\
\hline 1.0 & 20.0 & 4.0 & 12.7 \\
\hline 1.0 & 1.5 & 0.1 & 14.1 \\
\hline 1.0 & 1.5 & 0.2 & 14.3 \\
\hline 1.0 & 1.5 & 0.4 & 14.0 \\
\hline 1.0 & 1.5 & 0.8 & 14.2 \\
\hline 1.0 & 1.5 & 1.0 & 14.3 \\
\hline 1.0 & 1.5 & 2.0 & 10.2 \\
\hline 1.0 & 1.5 & 4.0 & 7.31 \\
\hline 1.0 & 1.5 & 8.0 & 4.27 \\
\hline 1.0 & 1.5 & 10.0 & 3.92 \\
\hline 1.0 & 1.5 & 12.0 & 3.32 \\
\hline 1.0 & 1.5 & 15.0 & 2.80 \\
\hline 1.0 & 1.5 & 20.0 & 1.94 \\
\hline 1.0 & 1.5 & 30.0 & 1.36 \\
\hline
\end{tabular}

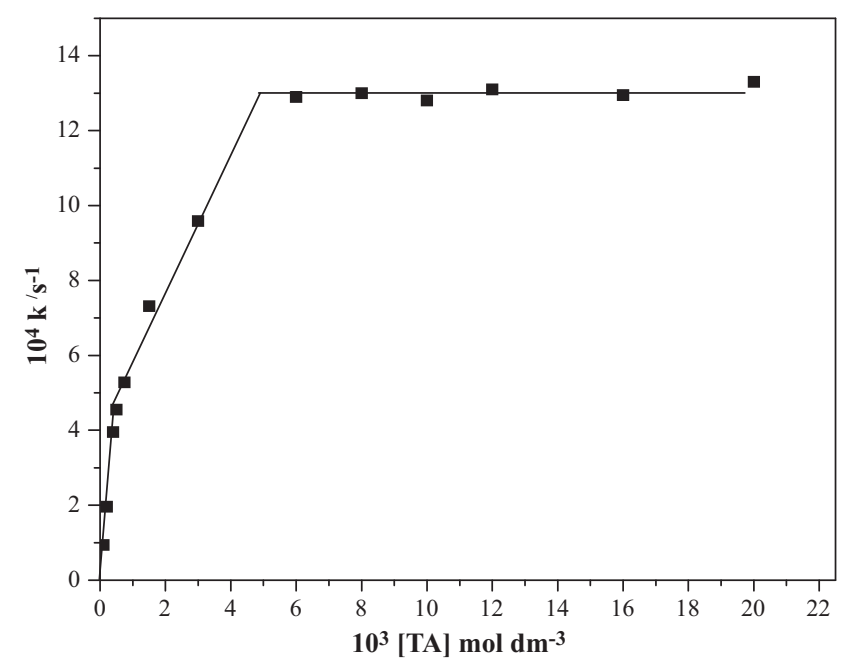

Fig. 2. A plot of $k^{\prime}$ versus [TA]. Experimental conditions are as in Table 1.

of $\log k^{\prime}$ versus $\log [\mathrm{TA}]$ in the concentration range of $0.1 \times 10^{-3}$ to $0.4 \times 10^{-3} \mathrm{~mol} \mathrm{dm}^{-3}$ was linear $(r=0.9984)$ with a unit slope, indicating a first-order dependence of the rate on $[\mathrm{TA}]_{0}$. Further, a plot of $k^{\prime}$ versus $[\mathrm{TA}]_{\mathrm{o}}$ in this concentration range was linear $(r=0.9999)$ passing through the origin, confirming the first-order dependence on $[\mathrm{TA}]_{\mathrm{o}}$. A log-log plot of rate versus TA in the concentration range of $0.5 \times 10^{-3}$ to $6.0 \times 10^{-3} \mathrm{~mol} \mathrm{dm}^{-3}$ was linear $(r=0.9998)$ with a slope less than unity $(0.47)$ and a plot of $k^{\prime}$ versus $[\mathrm{TA}]_{\mathrm{o}}$ in this concentration range was linear $(r=0.9870)$ with a $y$-intercept, confirming the order as less than unity with respect to $[\mathrm{TA}]_{\mathrm{O}}$. The order with respect to $[\mathrm{TA}]_{\mathrm{o}}$ in the concentration range of $8.0 \times 10^{-3}$ to $20.0 \times 10^{-3} \mathrm{~mol} \mathrm{dm}^{-3}$ exhibits zero-order kinetics. However, the log-log plot for the entire range studied $\left(0.1 \times 10^{-3}\right.$ to $20.0 \times 10^{-3} \mathrm{~mol} \mathrm{dm}^{-3}$ ) exhibit non-linear dependence of rate on [TA $]_{\mathrm{o}}$. Plot of $k^{\prime}$ versus [TA] for the complete concentration range studied is illustrated in Fig. 2.

The effect of $\mathrm{HClO}_{4}$ on the rate of the reaction was studied in the concentration range of $0.1 \times 10^{-3}$ to $30.0 \times 10^{-3} \mathrm{~mol} \mathrm{dm}^{-3}$ (Table 1). The reaction rate was decreased with increase in $\mathrm{HClO}_{4}$ in the concentration range of $1.0 \times 10^{-3}$ to $30.0 \times 10^{-3} \mathrm{~mol} \mathrm{dm}^{-3}$. A plot of $\log k^{\prime}$ versus $\log \left[\mathrm{HClO}_{4}\right]$ in the concentration range of $1.0 \times 10-^{3}$ to $10.0 \times 10^{-3} \mathrm{~mol} \mathrm{dm}^{-3}$ was linear $(r=0.9959)$ with a negative slope less than unity $(-0.60)$. Further, a plot of $k^{\prime}$ versus $\left[\mathrm{H}^{+}\right]$in the same range was fairly linear $(r=0.9724)$ with an intercept, confirming the order to be less than unity. Furthermore, at lower concentration range of $0.1 \times 10^{-3}$ to $0.8 \times 10^{-3} \mathrm{~mol} \mathrm{dm}^{-3}$, the rate exhibits zero-order kinetics whereas at higher concentrations of $\mathrm{HClO}_{4}$ in the range of $12.0 \times 10^{-3}$ to $30.0 \times 10^{-3} \mathrm{~mol} \mathrm{dm}^{-3}$, the reaction shows inverse first-order dependence. However, the $\log -\log$ plot of rate versus $\mathrm{HClO}_{4}$ for the entire range studied $\left(0.1 \times 10^{-3}\right.$ to $\left.30.0 \times 10^{-3} \mathrm{~mol} \mathrm{dm}^{-3}\right)$ exhibit non-linear dependence of rate on $\left[\mathrm{HClO}_{4}\right]$. Plot of $k^{\prime}$ versus $\left[\mathrm{HClO}_{4}\right]$ for the complete concentration range studied $\left(0.1 \times 10^{-3}\right.$ to $\left.30.0 \times 10^{-3} \mathrm{~mol} \mathrm{dm}^{-3}\right)$ is presented in Fig. 3.

The effect of initially added benzenesulfonamide (BSA) on the rate of the reaction was studied in the concentration range from $1.0 \times 10^{-3}$ to $6.0 \times 10^{-3} \mathrm{~mol} \mathrm{dm}^{-3}$, keeping all other experimental conditions constant. It was found that benzenesulfonamide had no significant effect on the reaction rate, suggesting its noninvolvement in pre-equilibrium to the rate-determining step. Ionic strength $(I)$ of the medium was varied by varying the concentration of sodium perchlorate $\left(0.1 \mathrm{~mol} \mathrm{dm}^{-3}\right.$ to $\left.0.4 \mathrm{~mol} \mathrm{dm}^{-3}\right)$. No significant effect on the rate of reaction was noticed. It indicates the involvement of non-ionic species in the rate-determining step. Hence, no attempt was made to keep ionic strength of the medium 


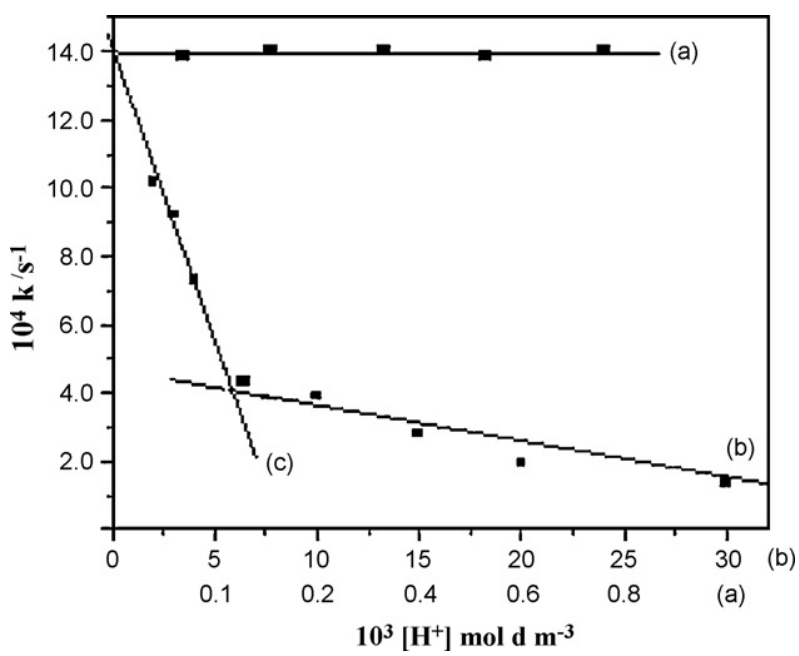

Fig. 3. A plot of $k^{\prime}$ versus $\left[\mathrm{H}^{+}\right]$. Experimental conditions are as in Table 1 .

constant during kinetic runs in acid medium. Addition of halide ions, $\mathrm{Cl}^{-}$or $\mathrm{Br}^{-}$ions in the form of their sodium salts $\left(1.0 \times 10^{-3}\right.$ to $10.0 \times 10^{-3} \mathrm{~mol} \mathrm{dm}^{-3}$ ) demonstrated no pronounced effect on the rate of reaction. This suggests that no interhalogen or bromine is formed during the reaction sequence and that there is a direct interaction of oxidizing species with the substrate. Solvent isotope effect was studied using $\mathrm{D}_{2} \mathrm{O}$. It was noticed that the reaction rate was further retarded with $k^{\prime}=5.45 \times 10^{-4} \mathrm{~s}^{-1}$ in $\mathrm{D}_{2} \mathrm{O}$. The rate of the reaction in $\mathrm{H}_{2} \mathrm{O}$ is $7.31 \times 10^{-4} \mathrm{~s}^{-1}$, leading to a solvent isotope effect $k^{\prime}\left(\mathrm{H}_{2} \mathrm{O}\right) / k^{\prime}\left(\mathrm{D}_{2} \mathrm{O}\right)=1.34$. The influence of temperature on the reaction rate was studied by performing the kinetic runs at different temperatures, in the range of 293 to $313 \mathrm{~K}$, keeping the other experimental conditions constant. From the linear Arrhenius plot of $\log k^{\prime}$ versus $1 / T(r=0.9937)$, values of activation parameters $\left(E_{a}, \Delta H^{\neq}, \Delta S^{\neq}, \Delta G^{\neq}\right.$and $\left.\log A\right)$ for overall reaction were computed. The results obtained are presented in Table 2. Addition of the reaction mixture to aqueous acrylamide solution did not initiate polymerization, showing the absence of free radical species. It indicates the non-radical pathways in the reaction sequence.

\subsection{Kinetics of oxidation of $\mathrm{TA}$ by $\mathrm{BAB}$ in $\mathrm{NaOH}$ medium catalyzed by $\operatorname{Pd}(\mathrm{II})$}

In the presence of excess of $[\mathrm{TA}]_{\mathrm{o}}$, the rate was first-order in $[\mathrm{BAB}]_{\mathrm{o}}$, since plots of $\log [\mathrm{BAB}]_{\mathrm{o}}$ versus time were linear $(r>0.9910)$ at fixed $[\mathrm{TA}]_{0},[\mathrm{NaOH}],[\mathrm{Pd}(\mathrm{II})]$ and temperature. The pseudo first-

Table 2

Influence of temperature on the reaction rate and activation parameters for the oxidation of TA by BAB in acid medium ${ }^{\mathrm{a}}$.

\begin{tabular}{lcc}
\hline Temperature & $(\mathrm{K}) k^{\prime}\left(\times 10^{4} \mathrm{~s}^{-1}\right)$ & $k_{3}\left(\times 10^{4} \mathrm{~s}^{-1}\right)$ \\
& $\mathrm{A}$ & $\mathrm{B}$ \\
\hline 293 & 3.73 & 6.02 \\
298 & 4.37 & 8.71 \\
303 & 7.31 & 14.3 \\
308 & 9.77 & 18.2 \\
313 & 15.4 & 25.0 \\
$E_{a}\left(\mathrm{~kJ} \mathrm{~mol}^{-1}\right)$ & 66.6 & 53.6 \\
$\Delta H^{\neq}\left(\mathrm{kJ} \mathrm{mol}^{-1}\right)$ & $64.1 \pm 0.01$ & $51.0 \pm 0.01$ \\
$\Delta G^{\neq}\left(\mathrm{kJ} \mathrm{mol}^{-1}\right)$ & $92.6 \pm 0.28$ & $94.7 \pm 0.84$ \\
$\Delta S^{\neq}\left(\mathrm{JK}^{-1} \mathrm{~mol}^{-1}\right)$ & $-93.8 \pm 0.29$ & $-143.8 \pm 1.9$ \\
$\log A$ & $8.7 \pm 0.06$ & $6.7 \pm 0.05$ \\
\hline
\end{tabular}

A, rate constants and activation parameters for the overall reaction; $B$, rate constants and activation parameters for the rate-determining step.

a $[\mathrm{BAB}]_{0}=1.0 \times 10^{-4} \mathrm{~mol} \mathrm{dm}^{-3}$;

$\left[\mathrm{HClO}_{4}\right]=4.0 \times 10^{-3} \mathrm{~mol} \mathrm{dm}{ }^{-3}$.
Table 3

Influence of oxidant, substrate, alkali and catalyst concentrations on the reaction rate at $303 \mathrm{~K}^{\mathrm{a}}$.

\begin{tabular}{llclc}
\hline $\begin{array}{l}{[\mathrm{BAB}]_{\mathrm{o}}\left(\times 10^{4}\right.} \\
\left.\mathrm{mol} \mathrm{dm}{ }^{-3}\right)\end{array}$ & $\begin{array}{l}{[\mathrm{TA}]_{\mathrm{o}}\left(\times 10^{3}\right.} \\
\left.\mathrm{mol} \mathrm{dm})^{-3}\right)\end{array}$ & $\begin{array}{l}{[\mathrm{NaOH}]\left(\times 10^{3}\right.} \\
\left.\mathrm{mol} \mathrm{dm}{ }^{-3}\right)\end{array}$ & $\begin{array}{l}{[\mathrm{Pd}(\mathrm{II})]\left(\times 10^{6}\right.} \\
\left.\mathrm{mol} \mathrm{dm})^{-3}\right)\end{array}$ & $k^{\prime}\left(\times 10^{4} \mathrm{~s}^{-1}\right)$ \\
\hline 0.5 & 1.5 & 4.0 & 6.0 & 5.20 \\
0.75 & 1.5 & 4.0 & 6.0 & 5.14 \\
1.0 & 1.5 & 4.0 & 6.0 & 5.06 \\
2.0 & 1.5 & 4.0 & 6.0 & 5.18 \\
5.0 & 1.5 & 4.0 & 6.0 & 5.24 \\
1.0 & 0.5 & 4.0 & 6.0 & 5.10 \\
1.0 & 0.75 & 4.0 & 6.0 & 4.92 \\
1.0 & 1.5 & 4.0 & 6.0 & 5.06 \\
1.0 & 3.0 & 4.0 & 6.0 & 4.96 \\
1.0 & 6.0 & 4.0 & 6.0 & 5.21 \\
1.0 & 1.5 & 1.0 & 6.0 & 2.04 \\
1.0 & 1.5 & 2.0 & 6.0 & 3.16 \\
1.0 & 1.5 & 4.0 & 6.0 & 5.06 \\
1.0 & 1.5 & 8.0 & 6.0 & 8.32 \\
1.0 & 1.5 & 10.0 & 6.0 & 9.68 \\
1.0 & 1.5 & 4.0 & 3.0 & 2.69 \\
1.0 & 1.5 & 4.0 & 6.0 & 5.06 \\
1.0 & 1.5 & 4.0 & 8.0 & 7.50 \\
1.0 & 1.5 & 4.0 & 12.0 & 25.0 \\
1.0 & 1.5 & 4.0 & & 25.6 \\
\hline
\end{tabular}

a $I=0.30 \mathrm{~mol} \mathrm{dm}^{-3}$

order rate constant was unaffected by the variation in $[B A B]_{0}$ (Table 3), confirming a first-order dependence of the rate on $[\mathrm{BAB}]_{\mathrm{o}}$. It is seen that in Table 3, the values of $k^{\prime}$ are unaffected with variation in $[\mathrm{TA}]_{\mathrm{o}}$. This result denotes that the order with respect to $[\mathrm{TA}]_{\mathrm{o}}$ is zero. The rate of the reaction increases with increase in $[\mathrm{NaOH}]$ (Table 3) and a log-log plot of rate versus $[\mathrm{NaOH}]$ was found to be linear $(r=0.9916)$ with a slope less than unity $(0.70)$ The rate increased with an increase in [Pd(II)] catalyst (Table 3) and the slope of $\log k^{\prime}$ versus $\log [\mathrm{Pd}(\mathrm{II})]$ plot $(r=0.9825)$ was found to be unity, thus illustrating the first-order dependence of rate on [Pd(II)]. Addition of benzenesulfonamide $\left(1.0 \times 10^{-3}\right.$ to $\left.6.0 \times 10^{-3} \mathrm{~mol} \mathrm{dm}^{-3}\right)$ and $\mathrm{NaCl}$ or $\mathrm{NaBr}\left(1.0 \times 10^{-3}\right.$ to $\left.10.0 \times 10^{-3} \mathrm{~mol} \mathrm{dm}^{-3}\right)$ had no pronounced effect on the reaction rate. An increase in ionic strength (I) of the reaction system by addition of $\mathrm{NaClO}_{4}$ in a range of $0.1-0.4 \mathrm{~mol} \mathrm{dm}^{-3}$ increased the rate of the reaction. The rate constants at $0.1,0.2,0.3$, and $0.4 \mathrm{~mol} \mathrm{dm}^{-3}$ were found to be $3.58,4.32$, 5.06 and $6.20 \times 10^{-4} \mathrm{~s}^{-1}$, respectively. The effect of ionic strength on the rate constant is explained by Bronsted and Bjerrum equation [17]. This equation shows that a plot of $\log k^{\prime}$ versus $I^{1 / 2}$ would be linear and the slope depends on the charges of the reacting ions. In the present case such a plot is linear (Fig. $4 ; r=0.9913$ ) with a pos-

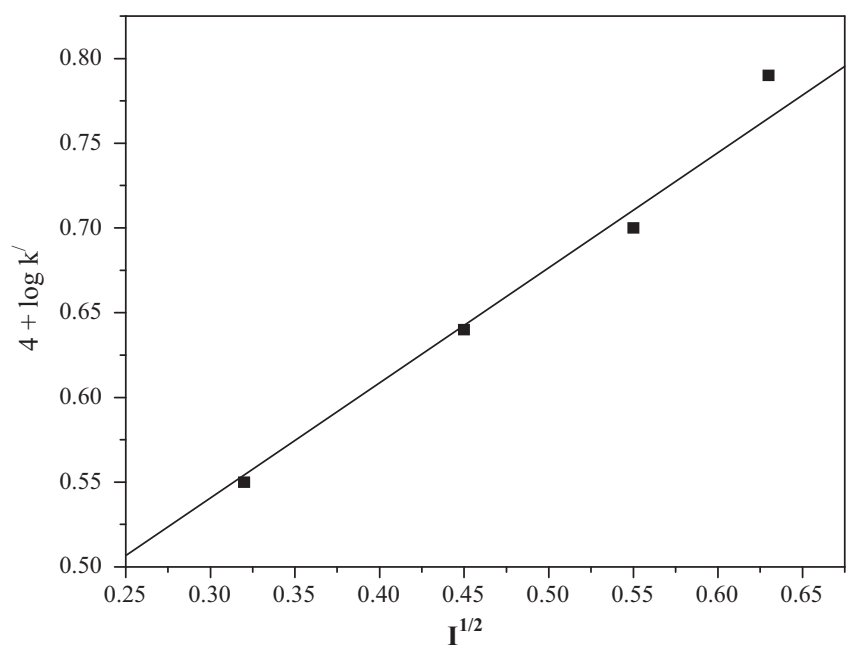

Fig. 4. Plot of $\log k^{\prime}$ versus $\mathrm{I}^{1 / 2}$. Experimental conditions are as in Table 3. 
Table 4

Influence of temperature on the reaction rate and activation parameters for the oxidation of TA by BAB in alkaline medium with and without Pd (II) catalyst ${ }^{\mathrm{a}}$.

\begin{tabular}{lcc}
\hline Temperature $(\mathrm{K})$ & \multicolumn{1}{c}{$k^{\prime}\left(\times 10^{4} \mathrm{~s}^{-1}\right)$} & $K_{C}\left(\times 10^{2}\right)$ \\
& $\mathrm{A}$ & $\mathrm{B}$ \\
\hline 293 & $2.13(0.25)$ & 1.04 \\
298 & $3.02(0.40)$ & 1.46 \\
303 & $5.06(0.79)$ & 2.37 \\
308 & $7.94(1.20)$ & 3.74 \\
313 & $11.52(2.09)$ & 5.24 \\
$E_{a}\left(\mathrm{~kJ} \mathrm{~mol}^{-1}\right)$ & $73.0(95.8)$ & 63.8 \\
$\Delta H^{\neq}\left(\mathrm{kJ} \mathrm{mol}^{-1}\right)$ & $70.5 \pm 0.13(93.3 \pm 0.01)$ & $61.3 \pm 0.01$ \\
$\Delta G^{\neq}\left(\mathrm{kJ} \mathrm{mol}^{-1}\right)$ & $93.4 \pm 0.16(95.0 \pm 0.70)$ & $59.3 \pm 0.57$ \\
$\Delta S^{\neq}\left(\mathrm{kJ}^{-1} \mathrm{~mol}^{-1}\right)$ & $-75.8 \pm 0.36(-25.4 \pm 0.25)$ & $6.36 \pm 1.77$ \\
$\log A$ & $11.0 \pm 0.03(14.7 \pm 0.48)$ & $11.2 \pm 0.77$ \\
\hline
\end{tabular}

A, values outside the parenthesis are the rate constants and activation parameters for $\mathrm{Pd}(\mathrm{II})$ catalyzed reactions. A, values inside the parenthesis are the rate constants and activation parameters for the uncatalyzed reactions. B, values of catalytic constants and activation parameters with respect to $\mathrm{Pd}(\mathrm{II})$ catalyst.

a $[\mathrm{BAB}]_{\mathrm{o}}=1.0 \times 10^{-4} \mathrm{~mol} \mathrm{dm}^{-3} ; \quad[\mathrm{TA}]_{0}=1.5 \times 10^{-3} \mathrm{~mol} \mathrm{dm}^{-3} ; \quad[\mathrm{NaOH}]=4.0 \times$ $10^{-3} \mathrm{~mol} \mathrm{dm}^{-3}$ and in catalyzed reaction $[\mathrm{Pd}(\mathrm{II})]=6.0 \times 10^{-6} \mathrm{~mol} \mathrm{dm}^{-3}$; $I=0.30 \mathrm{~mol} \mathrm{dm}^{-3}$.

itive slope. It suggests the involvement of similar charges (in the present case negative ionic charges) in the rate-determining step of the proposed mechanism. Hence, the ionic strength of the system was maintained at a constant value of $0.30 \mathrm{~mol} \mathrm{dm}^{-3}$ using a concentrated solution of $\mathrm{NaClO}_{4}$ for all the kinetic runs in alkaline medium in order to swamp the reaction. Rate studies made in $\mathrm{D}_{2} \mathrm{O}$ medium, showed that $k^{\prime}\left(\mathrm{D}_{2} \mathrm{O}\right)$ is $6.20 \times 10^{-4} \mathrm{~s}^{-1}$ while the corresponding $k^{\prime}\left(\mathrm{H}_{2} \mathrm{O}\right)$ is $5.06 \times 10^{-4} \mathrm{~s}^{-1}$ leading to a solvent isotope effect, $k^{\prime}\left(\mathrm{H}_{2} \mathrm{O}\right) / k^{\prime}\left(\mathrm{D}_{2} \mathrm{O}\right)$ of 0.82 . Activation parameters were calculated (Table 4 ) by studying the reaction at different temperatures (293-313 K) using Arhenuius plot $(r=0.9850)$. The presence of free radical species in the reaction mixture could not be proved.

\subsection{Reactive species of bromamine- $B$}

Organic N-haloamines are known to be mild oxidants in both acidic and alkaline media. As organic haloamines have similar chemical properties, it is expected that identical equilibria exist in solutions of these compounds [18]. Bromamine-B, which is analogous to chloramine- $T$ and chloramine- $B$, behaves like a strong electrolyte in both acidic and alkaline media. In general, BAB undergoes a two-electron change in its reactions. The oxidation potential of $\mathrm{BAB} / \mathrm{PhSO}_{2} \mathrm{NH}_{2}$ is $\mathrm{pH}$ dependent and decreases with an increase in the $\mathrm{pH}$ of the medium, having values of $1.14 \mathrm{~V}$ at $\mathrm{pH}$ 0.65 and $0.50 \mathrm{~V}$ at $\mathrm{pH} 12.0$. Depending on the $\mathrm{pH}$ of the medium, $\mathrm{BAB}\left(\mathrm{PhSO}_{2} \mathrm{NBrNa}\right)$ furnishes different types of reactive species [18-22]. The possible oxidizing species in acidified $\mathrm{BAB}$ solutions are $\mathrm{PhSO}_{2} \mathrm{NHBr}, \mathrm{PhSO}_{2} \mathrm{NBr}_{2}, \mathrm{HOBr}$ and perhaps $\mathrm{H}_{2} \mathrm{O}^{+} \mathrm{Br}$. In alkaline medium, where $\mathrm{PhSO}_{2} \mathrm{NBr}_{2}$ and $\mathrm{H}_{2} \mathrm{O}^{+} \mathrm{Br}$ do not exist, the expected reactive species are $\mathrm{PhSO}_{2} \mathrm{NHBr}, \mathrm{HOBr}, \mathrm{PhSO}_{2} \mathrm{~N}^{-} \mathrm{Br}$ and $\mathrm{OBr}^{-}$.

\subsection{Reactive species of Pd(II) catalyst}

Pd(II) catalysis and inhibition reactions have been reported in various redox reactions $[6,23,24]$. The redox reactions in the presence of $\mathrm{Pd}(\mathrm{II})$ have also shown a complex kinetics. Generally, the palladium complexes are somewhat less stable from both kinetic and thermodynamic sense, than their platinum analogues. They are known to form different complexes in alkaline solutions $[24,25]$ and the plausible $\mathrm{Pd}(\mathrm{II})$ complex species are $\left[\mathrm{Pd}(\mathrm{OH}) \mathrm{Cl}_{3}\right]^{2-}$, $\left[\mathrm{Pd}(\mathrm{OH})_{2} \mathrm{Cl}_{2}\right]^{2-}$ and probably $\left[\mathrm{Pd}(\mathrm{OH})_{4}\right]^{2-}$. Since the tetra-hydroxo complex of $\mathrm{Pd}(\mathrm{II}),\left[\mathrm{Pd}(\mathrm{OH})_{4}\right]^{2-}$ is relatively unstable, it has been ruled out as the catalytic species. Further, in the present investigations the acceleration of rate with increase in $\left[\mathrm{OH}^{-}\right]$and also zero effect of rate on $\left[\mathrm{Cl}^{-}\right]$on the rate of reaction clearly ruling out the possibility of $\left[\mathrm{Pd}(\mathrm{OH}) \mathrm{Cl}_{3}\right]^{2-}$ as the catalyst species. The facts presented above constrain us to assume that the $\left[\mathrm{Pd}(\mathrm{OH})_{2} \mathrm{Cl}_{2}\right]^{2-}$ complex ion is the reactive catalyst species in the present case. Similar species has been employed in our early work [6].

\subsection{Reaction scheme and rate law in acid medium}

The possible oxidizing species in acidified $\mathrm{BAB}$ solutions are $\mathrm{PhSO}_{2} \mathrm{NHBr}, \mathrm{PhSO}_{2} \mathrm{NBr}_{2}, \mathrm{HOBr}$ and possibly $\mathrm{H}_{2} \mathrm{O}^{+} \mathrm{Br}$. However, since the involvement of $\mathrm{PhSO}_{2} \mathrm{NBr}_{2}$ as the reactive species predicts a second-order dependence of the rate on $[\mathrm{BAB}]_{\mathrm{o}}$, which is contrary to the experimental observation, $\mathrm{PhSO}_{2} \mathrm{NBr}_{2}$ is ruled out as the oxidizing species. If $\mathrm{HOBr}$ is the active species, then a firstorder retardation of the rate by the added benzenesulfonamide $\left(\mathrm{PhSO}_{2} \mathrm{NH}_{2}\right)$ should have been observed, which is not found to be so, thereby ruling out the involvement of $\mathrm{HOBr}$ in the reaction sequence. Further, these two species are present in a very low concentrations at the experimental conditions employed [20]. Hardy and Johnston [18], who studied the $\mathrm{pH}$ dependent relative concentrations of the species present in acidified CAT solutions of comparable molarities, have shown that $\mathrm{CH}_{3} \mathrm{C}_{6} \mathrm{H}_{4} \mathrm{SO}_{2} \mathrm{NHCl}$ is the likely oxidizing species. In view of the similarity in properties of CAT and BAB [18], similar argument can be extended to BAB also. Hence in the present investigations, $\mathrm{PhSO}_{2} \mathrm{NHBr}$ is assumed as the most probable oxidizing reactive species. Further, Narayanan and Rao [26] and Subhashini et al. [27] have reported that CAT and $\mathrm{CAB}$ can be further protonated as in the following Eqs. (2) and (3), respectively:

$$
\begin{aligned}
& \mathrm{CH}_{3} \mathrm{C}_{6} \mathrm{H}_{4} \mathrm{SO}_{2} \mathrm{NHCl}+\mathrm{H}^{+} \rightleftharpoons \mathrm{CH}_{3} \mathrm{C}_{6} \mathrm{H}_{4} \mathrm{SO}_{2} \mathrm{~N}+\mathrm{H}_{2} \mathrm{Cl} \\
& \mathrm{C}_{6} \mathrm{H}_{5} \mathrm{SO}_{2} \mathrm{NHCl}+\mathrm{H}^{+} \rightleftharpoons \mathrm{C}_{6} \mathrm{H}_{5} \mathrm{SO}_{2} \mathrm{~N}+\mathrm{H}_{2} \mathrm{Cl}
\end{aligned}
$$

We believe that in the case of $\mathrm{BAB}$ also, protonated species $\mathrm{PhSO}_{2} \mathrm{~N}^{+} \mathrm{H}_{2} \mathrm{Br}$ is involved. In the present case however, an inverse-fractional-order in $\left[\mathrm{H}^{+}\right]$suggests that the deprotonation of $\mathrm{PhSO}_{2} \mathrm{~N}^{+} \mathrm{H}_{2} \mathrm{Br}$ results in the formation of $\mathrm{PhSO}_{2} \mathrm{NHBr}$, which is likely to be the active oxidizing species involved in the mechanism.

In the light of these considerations, the mechanism for the oxidation of TA with BAB in acid medium is formulated as given in Scheme 1. In the initial acid retarding fast equilibrium step (step (i)), of Scheme 1, deprotonation of $\mathrm{PhSO}_{2} \mathrm{~N}^{+} \mathrm{H}_{2} \mathrm{Br}$ takes place to give the conjugate acid $\mathrm{PhSO}_{2} \mathrm{NHBr}$. In the successive equilibrium fast step (ii), $\mathrm{PhSO}_{2} \mathrm{NHBr}$ directly reacts with the substrate to form the substrate-oxidant complex (I). This decomposes in the ratedetermining step (rds) to give another intermediate complex (II) with the elimination of $\mathrm{PhSO}_{2} \mathrm{NH}_{2}$. Further, complex (II) reacts with one more mole of the oxidant species followed by several fast steps leading to the formation of the main product.

If $[\mathrm{BAB}]_{t}$ represents the total concentration of $\mathrm{BAB}$, then:

$[\mathrm{BAB}]_{t}=\left[\mathrm{PhSO}_{2} \mathrm{~N}^{+} \mathrm{H}_{2} \mathrm{Br}\right]+\left[\mathrm{PhSO}_{2} \mathrm{NHBr}\right]+[\operatorname{complex}(\mathrm{I})], \quad$ from which:

$[\operatorname{complex}(\mathrm{I})]=\frac{K_{1} K_{2}[\mathrm{BAB}]_{t}[\mathrm{TA}]}{\left[\mathrm{H}^{+}\right]+K_{1}+K_{1} K_{2}[\mathrm{TA}]}$

From the slow/rate-determining step (iii) of Scheme 1:

Rate $=-\frac{d[B A B]}{d t}=k_{3}[\operatorname{complex}(I)]$

Substitution for [complex (I)] from Eq. (4) into Eq. (5), we get the following rate law:

Rate $=\frac{K_{1} K_{2} k_{3}[\mathrm{BAB}]_{t}[\mathrm{TA}]}{\left[\mathrm{H}^{+}\right]+K_{1}+K_{1} K_{2}[\mathrm{TA}]}$

Rate law (6) is in good agreement with the observed results such as first-order in $[\mathrm{BAB}]_{\mathrm{o}}$, less than unity order in $[\mathrm{TA}]_{\mathrm{o}}$ and also inverse less than unity order with respect to $\left[\mathrm{H}^{+}\right]$at the concentrations of $\mathrm{TA}$ in the range of $0.5 \times 10^{-3}$ to $6.0 \times 10^{-3} \mathrm{~mol} \mathrm{dm}^{-3}$. 
(i) $\mathrm{PhSO}_{2} \mathrm{~N}^{+} \mathrm{H}_{2} \mathrm{Br} \underset{\text { fast }}{\stackrel{\mathrm{K}_{1}}{\rightleftharpoons}} \mathrm{PhSO}_{2} \mathrm{NHBr}+\mathrm{H}^{+}$

(ii)

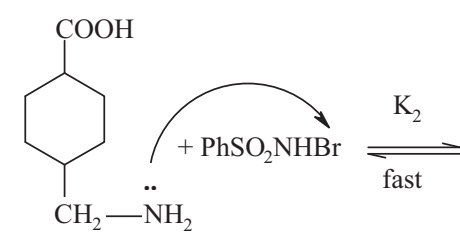

(TA)

(iii)<smiles>C[C@H](NCC1CCC(C(=O)O)CC1)N[NH2+][O-]</smiles><smiles>O=C(O)NNCC1CCC(C(=O)O)CC1</smiles>

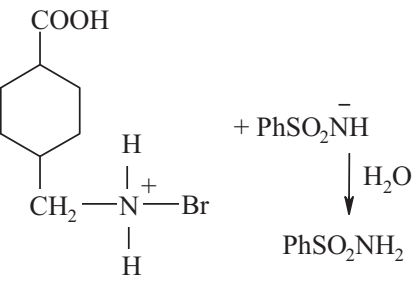

complex (II)

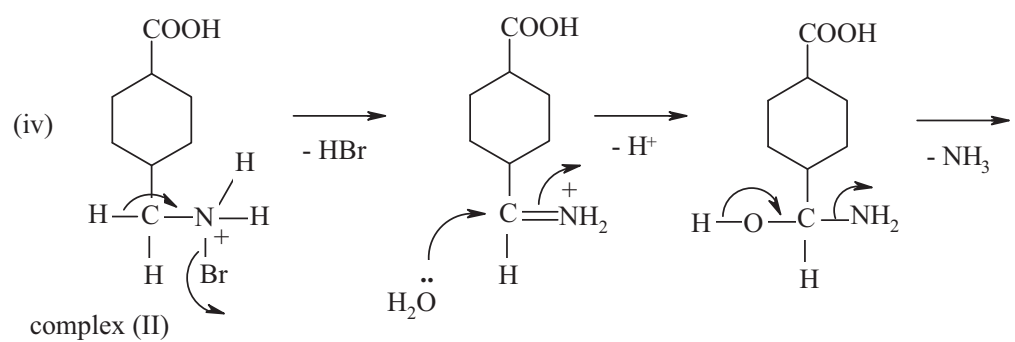
complex (II)<smiles>O=C(O)C1CCC(C(=O)O)CC1</smiles>

Scheme 1. A general mechanistic scheme for the oxidation of TA by BAB in acid medium.

Since rate $=k^{\prime}[\mathrm{BAB}]_{t}$, under pseudo-first-order conditions of $[\mathrm{BAB}]_{\mathrm{o}} \ll[\mathrm{TA}]_{\mathrm{o}}$, then:

$k^{\prime}=\frac{K_{1} K_{2} k_{3}[\mathrm{TA}]}{\left[\mathrm{H}^{+}\right]+K_{1}+K_{1} K_{2}[\mathrm{TA}]}$

Eq. (6) can be analyzed in detail as follows:

(a) Variation with respect to $[\mathrm{TA}]_{0}$ :

Case (i): If $\left[\mathrm{H}^{+}\right]+K_{1} \ggg K_{1} K_{2}$ [TA], the rate law (6) becomes:

Rate $=\frac{K_{1} K_{2} k_{3}[\mathrm{BAB}]_{t}[\mathrm{TA}]}{\left[\mathrm{H}^{+}\right]+K_{1}}$

The above rate law (8) shows a first-order kinetics with respect to $[\mathrm{TA}]_{0}$ as observed in the concentration range of $0.1 \times 10^{-3}$ to $0.4 \times 10^{-3} \mathrm{~mol} \mathrm{dm}^{-3}$.

Case (ii): If $K_{1} K_{2}[\mathrm{TA}] \ggg K_{1}+\left[\mathrm{H}^{+}\right]$, the rate law (6) becomes:

Rate $=k_{3}[\mathrm{BAB}]_{t}$

The above rate law (9) shows a zero-order kinetics with respect to $[\mathrm{TA}]_{\mathrm{o}}$ as observed in the concentration range of $12.0 \times 10^{-3}$ to $20.0 \times 10^{-3} \mathrm{~mol} \mathrm{dm}^{-3}$. The detailed kinetic studies were carried out under intermediate concentrations of above two extremes $\left(0.5 \times 10^{-3}\right.$ to $\left.6.0 \times 10^{-3} \mathrm{~mol} \mathrm{dm}^{-3}\right)$. All these results are in conformity with the derived rate law (6).

(b) Variation with respect to $\left[\mathrm{H}^{+}\right]$:
Case (i): If [ $\left.\mathrm{H}^{+}\right] \ggg K_{1}+K_{1} K_{2}[\mathrm{TA}]$, the rate law (6) becomes:

Rate $=\frac{K_{1} K_{2} k_{3}[\mathrm{BAB}]_{\mathrm{t}}[\mathrm{TA}]}{\left[\mathrm{H}^{+}\right]}$

The above rate law (10) shows inverse first-order dependence with respect to $\left[\mathrm{H}^{+}\right]$as observed in the concentration range of $12.0 \times 10^{-3}$ to $30.0 \times 10^{-3} \mathrm{~mol} \mathrm{dm}^{-3}$.

Case (ii): If $K_{1}+K_{1} K_{2}[\mathrm{TA}] \ggg\left[\mathrm{H}^{+}\right]$, the rate law (6) becomes:

Rate $=\frac{K_{1} K_{2} k_{3}[\mathrm{BAB}]_{\mathrm{t}}[\mathrm{TA}]}{K_{1}+K_{1} K_{2}[\mathrm{TA}]}$

The above rate law (11) shows a zero-order dependence with respect to $\left[\mathrm{H}^{+}\right]$as observed in the concentration range of $0.1 \times 10^{-3}$ to $0.8 \times 10^{-3} \mathrm{~mol} \mathrm{dm}^{-3}$. The detailed kinetic studies were carried out under intermediate concentrations of above two extremes $\left(1.0 \times 10^{-3}\right.$ to $\left.10.0 \times 10^{-3} \mathrm{~mol} \mathrm{dm}^{-3}\right)$. All these results are in conformity with the derived rate law (6).

Further, Eq. (7) can be transformed as:

$\begin{aligned} \frac{1}{k^{\prime}} & =\frac{\left[\mathrm{H}^{+}\right]}{K_{1} K_{2} k_{3}[T A]}+\frac{1}{K_{2} k_{3}[T A]}+\frac{1}{k_{3}} \\ \frac{1}{k^{\prime}} & =\frac{1}{[\mathrm{TA}]}\left\{\frac{H^{+}}{K_{1} K_{2} k_{3}}+\frac{K_{1}}{K_{2} k_{3}}\right\}+\frac{1}{k_{3}}\end{aligned}$ 


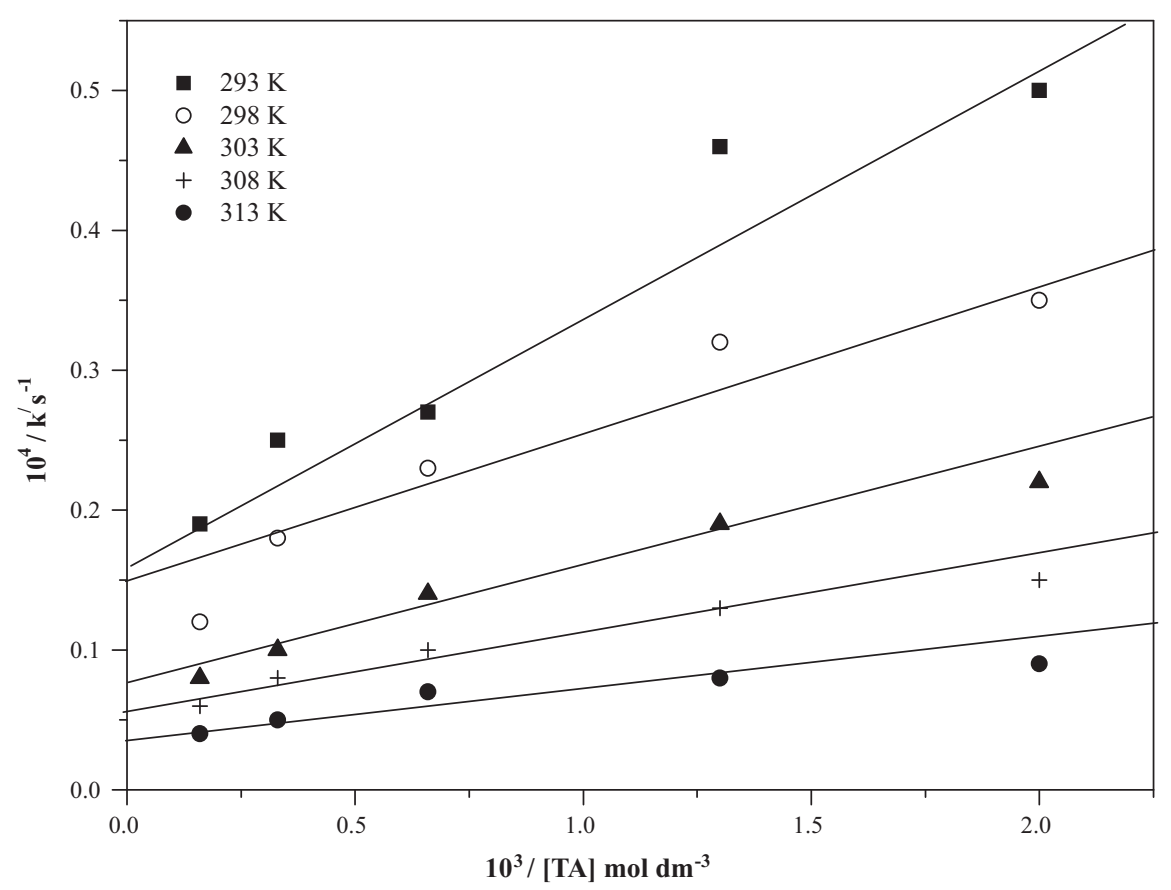

Fig. 5. Plots of $1 / k^{\prime}$ versus $1 /[\mathrm{TA}]$ at different temperatures in acid medium. Experimental conditions are as in Table 1.

$\frac{1}{k^{\prime}}=\left[\mathrm{H}^{+}\right]\left\{\frac{1}{K_{1} K_{2} k_{3}[\mathrm{TA}]}\right\}+\left\{\frac{1}{K_{2} k_{3}[\mathrm{TA}]}+\frac{1}{k_{3}}\right\}$

A plot of $1 / k^{\prime}$ versus $1 /[\mathrm{TA}]$ from Eq. (13) yields a:

slope $=\left\{\frac{\left[\mathrm{H}^{+}\right]}{K_{1} K_{2} k_{3}}+\frac{K_{1}}{K_{2} k_{3}}\right\}$

and an intercept $=1 / k_{3}$. Similarly, a plot of $1 / k^{\prime}$ versus $\left[\mathrm{H}^{+}\right]$from Eq. (14) yields a:

Slope $=\frac{1}{K_{1} K_{2} k_{3}[\mathrm{TA}]}$ and an intercept $=\left\{\frac{1}{K_{2} k_{3}[\mathrm{TA}]}+\frac{1}{k_{3}}\right\}$

Therefore, from the slopes and intercepts of Eqs. (13) and (14), the values of the equilibrium constants $K_{1}$ and $K_{2}$, and decomposition constant $k_{3}$ were calculated for the standard run with $[\mathrm{BAB}]_{\mathrm{o}}=1.0 \times 10^{-4} \mathrm{~mol} \mathrm{dm}^{-3} ;[\mathrm{TA}]_{\mathrm{o}}=1.5 \times 10^{-3} \mathrm{~mol} \mathrm{dm}^{-3}$; $\left[\mathrm{HClO}_{4}\right]=4.0 \times 10^{-3} \mathrm{~mol} \mathrm{dm}^{-3}$ at $303 \mathrm{~K}$. The values obtained are $K_{1}=5.0 \times 10^{3} \mathrm{~mol} \mathrm{dm}^{-3}, \quad K_{2}=8.66 \times 10^{3} \mathrm{dm}^{3} \mathrm{~mol}^{-1}$ and $k_{3}=1.54 \times 10^{-3} \mathrm{~s}^{-1}$.

The proposed Scheme 1 is supported by the following experimental observations:

Michaelis-Menten type of kinetics [28] was followed to study the effect of $[\mathrm{TA}]_{\mathrm{o}}$ on the rate of reaction at different temperatures. The effect of $[\mathrm{TA}]_{\mathrm{o}}$ on the rate at different temperatures was shown by the plots of $1 / k^{\prime}$ versus $1 /[\mathrm{TA}]$ (Fig. $5 ; r>0.9875$ ) and the decomposition constant $k_{3}$ for the rate-determining step was calculated using Eq. (13) at each temperature. Activation parameters for the decomposition step of the TA-BAB complex (step (iii) of Scheme 1), were evaluated using Arrhenius plot of $\log k_{3}$ versus $1 / T(r=0.9824)$. These data are tabulated in Table 2 . A comparison with the activation parameters obtained for the composite reaction shows that the values mainly refer to the rate-determining step supporting the fact that reaction before the rate-determining step is fast, involving trivial activation energy.

Study of isotope effects on the reaction rate gives us information about the reaction mechanism during the rate-determining step. When measuring isotope effects for reactions involving a substitution of hydrogen with deuterium, the isotope effect would be expressed as $k^{\prime}\left(\mathrm{H}_{2} \mathrm{O}\right) / k^{\prime}\left(\mathrm{D}_{2} \mathrm{O}\right)$. It is interesting to note that the rate in $\mathrm{D}_{2} \mathrm{O}$ medium is slower than that in $\mathrm{H}_{2} \mathrm{O}$ and this can be explained based on the concept of solvent isotope. For a reaction involving a fast pre-equilibrium $\mathrm{H}^{+}$or $\mathrm{OH}^{-}$ion transfer, the rate increases in $\mathrm{D}_{2} \mathrm{O}$ medium. Since $\mathrm{D}_{3} \mathrm{O}^{+}$and $\mathrm{OD}^{-}$are a stronger acid and a stronger base than $\mathrm{H}_{3} \mathrm{O}^{+}$and $\mathrm{OH}^{-}$ions by a factor of $2-3$, a solvent isotope effect of this magnitude is to be expected $[29,30]$. The reverse holds for reactions involving retardation by $\mathrm{H}^{+}$or $\mathrm{OH}^{-}$ions. Hence the proposed mechanism is supported by the decrease in rate in $\mathrm{D}_{2} \mathrm{O}$ medium, indicating retardation by $\mathrm{H}^{+}$ion. The extent of solvent isotope effect, however, is small $\left(k^{\prime}\left(\mathrm{H}_{2} \mathrm{O}\right) / k^{\prime}\left(\mathrm{D}_{2} \mathrm{O}\right)=1.34\right)$ compared to the expected value, which can be referred to the inverse less than unity order dependence of rate on $\left[\mathrm{H}^{+}\right]$.

The proposed mechanism is supported by the moderate values of energy of activation and also on other activation parameters. The moderate value of the energy of activation and high positive value of enthalpy of activation indicate that the transition state is highly solvated. The observed entropy of activation value is large and negative. It may be interpreted that the fraction of collisions become more stringent and decomposition of activated complex is quite a slow process. Further, the proposed mechanism is also in agreement with the observed negligible influence of benzenesulfonamide, halide ions and ionic strength of the medium on the reaction rate.

\subsection{Reaction scheme and rate law in alkaline medium}

In alkaline solutions of $\mathrm{BAB}$, the anion $\mathrm{PhSO}_{2} \mathrm{~N}^{-} \mathrm{Br}$ becomes important and the following equilibria are reported [18]:

$\mathrm{PhSO}_{2} \mathrm{~N}^{-} \mathrm{Br}+\mathrm{H}_{2} \mathrm{O} \rightleftharpoons \mathrm{PhSO}_{2} \mathrm{NH}_{2}+\mathrm{OBr}^{-}$

$\mathrm{PhSO}_{2} \mathrm{~N}^{-} \mathrm{Br}+\mathrm{H}_{2} \mathrm{O} \rightleftharpoons \mathrm{PhSO}_{2} \mathrm{NHBr}+\mathrm{OH}^{-}$

$\mathrm{PhSO}_{2} \mathrm{NHBr}+\mathrm{H}_{2} \mathrm{O} \rightleftharpoons \mathrm{PhSO}_{2} \mathrm{NH}_{2}+\mathrm{HOBr}$

$\mathrm{PhSO}_{2} \mathrm{NHBr}+\mathrm{OH}^{-} \rightleftharpoons \mathrm{PhSO}_{2} \mathrm{NH}_{2}+\mathrm{OBr}^{-}$

Eqs. (15), (17) and (18) suggest rate retardation with the addition of benzenesulfonamide, while Eq. (16) predicts a decrease in rate by $\mathrm{OH}^{-}$ions. As these predictions are contrary to our experimental 
observations, the likely reactive species in the present investigations is the anion $\mathrm{PhSO}_{2} \mathrm{~N}^{-} \mathrm{Br}$.

Formation of the complex between oxidant and catalyst was demonstrated by recording the UV-vis spectra of BAB, Pd(II) and a mixture of both in aqueous alkaline medium (UV-vis spectra are recorded on UV-3101PC, UV-VIS-NIR Scanning Spectrophotometer, Shimadzu). Absorption maxima appear at $227 \mathrm{~nm}$ for BAB, 410 $\mathrm{nm}$ for Pd(II) and $401 \mathrm{~nm}$ for a mixture of both (Fig. 6). A hypsochromic shift of $9 \mathrm{~nm}$ from $410 \mathrm{~nm}$ to $401 \mathrm{~nm}$ of Pd(II) suggests that the complexation occurs between the oxidant $\mathrm{BAB}$ and the catalyst Pd(II).

In view of preceding discussion and experimental facts, Scheme 2 is put forwarded to explain the reaction mechanism of TA-BAB-Pd(II) reaction in alkaline medium. In a fast initial alkali accelerating equilibrium (step (i)) of Scheme 2, the conjugate acid $\mathrm{PhSO}_{2} \mathrm{NHBr}$, generates the anionic species $\mathrm{PhSO}_{2} \mathrm{~N}^{-} \mathrm{Br}$, which is the active oxidizing species. In the next slow/rate-determining step (step (ii)), the oxidizing anionic species complexes with the catalyst forming an intermediate complex (III). Substrate TA reacts with complex (III) forming another intermediate complex (IV) with the elimination of $\mathrm{PhSO}_{2} \mathrm{NH}_{2}$ and the catalyst species. This intermediate complex (IV) reacts with another mole of the oxidant species followed by several fast steps to yield the final product.

The total effective concentration of $\mathrm{BAB}$ is:

$[\mathrm{BAB}]_{t}=\left[\mathrm{PhSO}_{2} \mathrm{NHBr}\right]+\left[\mathrm{PhSO}_{2} \mathrm{~N}^{-} \mathrm{Br}\right]$

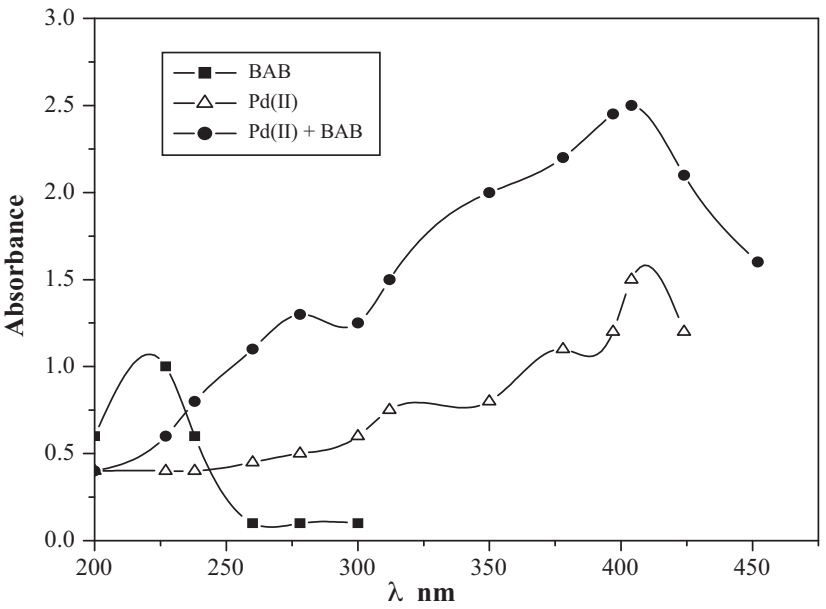

Fig. 6. UV-vis spectra of $B A B, P d(I I)$ and $B A B+P d(I I)$ complex.

By substituting for $\left[\mathrm{PhSO}_{2} \mathrm{NHBr}\right]$ from equilibrium (i) of Scheme 2 in Eq. (19) and solving for [ $\left.\mathrm{PhSO}_{2} \mathrm{~N}^{-} \mathrm{Br}\right]$, one obtains:

$\left[\mathrm{PhSO}_{2} \mathrm{~N}^{-} \mathrm{Br}\right]=\frac{K_{5}[\mathrm{BAB}]\left[\mathrm{OH}^{-}\right]}{\left[\mathrm{H}_{2} \mathrm{O}\right]+K_{5}\left[\mathrm{OH}^{-}\right]}$

(i) $\mathrm{PhSO}_{2} \mathrm{NHBr}+\mathrm{OH}^{-} \underset{\text { fast }}{\stackrel{\mathrm{K}_{5}}{\rightleftharpoons}} \mathrm{PhSO}_{2} \overline{\mathrm{NBr}}+\mathrm{H}_{2} \mathrm{O}$

(ii)

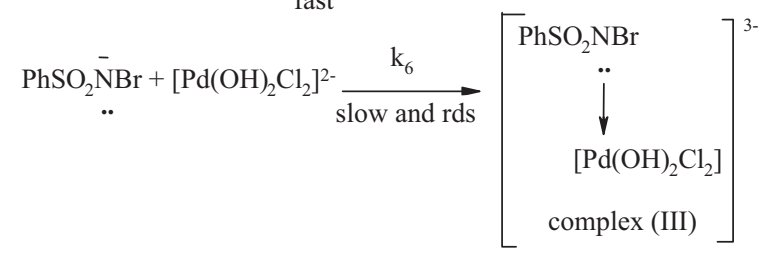

(iii)<smiles>NCC1CCC(C(=O)O)CC1</smiles>

(TA)

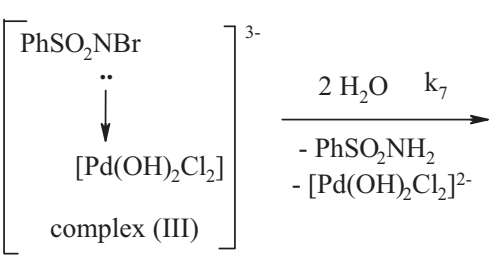<smiles>NC(=O)C1CCC(C(=O)O)CC1</smiles>

(iv)<smiles>N#CCC1CCC(C(=O)O)CC1</smiles><smiles>Br[Mg]Br</smiles><smiles>N=C(CCCO)C(CCCO)C1CCC(C(=O)O)CC1</smiles><smiles>NC(N)[C@H](O)C1CCC(C(=O)O)CC1</smiles>

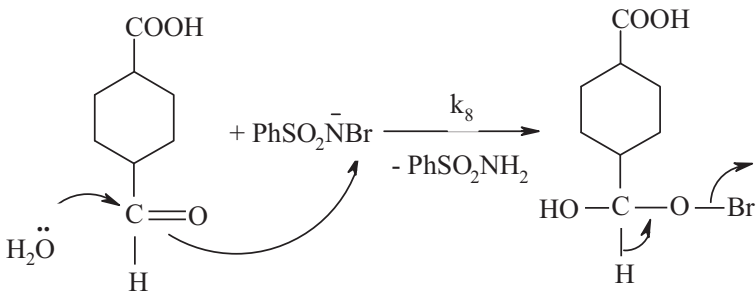<smiles>O=C(O)C1CCC(C(=O)O)CC1</smiles>

Scheme 2. A general mechanistic scheme for Pd(II) catalyzed oxidation of TA by BAB in alkaline medium. 
From slow/rate-determining step of Scheme 2:

Rate $=-\frac{d[\mathrm{BAB}]_{t}}{d t}=k_{6}\left[\mathrm{PhSO}_{2} \mathrm{~N}^{-} \mathrm{Br}\right][\mathrm{Pd}(\mathrm{II})]$

By substituting for $\left[\mathrm{PhSO}_{2} \mathrm{~N}^{-} \mathrm{Br}\right]$ from Eq. (20) into Eq. (21), the following rate law is obtained:

Rate $=-\frac{d[\mathrm{BAB}]_{t}}{d t}=\frac{K_{5} k_{6}[\mathrm{BAB}]_{t}\left[\mathrm{OH}^{-}\right][\mathrm{Pd}(\mathrm{II})]}{\left[\mathrm{H}_{2} \mathrm{O}\right]+K_{5}\left[\mathrm{OH}^{-}\right]}$

This rate law satisfactorily fits well to the experimental results wherein a first-order dependence of rate on each $[\mathrm{BAB}]_{0}$ and $[\mathrm{Pd}(\mathrm{II})]$, less than unity order on $\left[\mathrm{OH}^{-}\right]$and the lack of effect of the $[\mathrm{TA}]_{\mathrm{o}}$ and $[\mathrm{BSA}]$ on the rate of reaction was noticed. In alkaline medium, the solvent isotope studies show that $k^{\prime}\left(\mathrm{H}_{2} \mathrm{O}\right) / k^{\prime}\left(\mathrm{D}_{2} \mathrm{O}\right)<1$. This is generally correlated with the fact that $\mathrm{OD}^{-}$ion is a stronger base than $\mathrm{OH}^{-}$ion and in base catalyzed reactions, enhancement of rate in $\mathrm{D}_{2} \mathrm{O}$ medium can be expected according to the concept of solvent isotope theory $[29,30]$. However, the small magnitude of the isotopic effect (0.82) can be attributed to the less than unity order dependence on $\left[\mathrm{OH}^{-}\right]$. The mechanism proposed is congruous with the observed negligible effects of benzenesulfonamide, halide ions and also on the activation parameters.

It was also considered worthwhile to compare the reactivity of TA by BAB in absence of Pd(II) catalyst under the identical set of experimental conditions. The uncatalyzed reaction was carried out at different temperatures (293-313 K) and from the Arrhenius plot of $\log k^{\prime}$ versus $1 / T(r=0.9810)$, values of activation parameters for the uncatalyzed reaction were computed. These data are recorded in Table 4. It is seen from the Table 4 that the Pd(II) catalyzed reaction rate is found to be 6 -fold faster than the uncatalyzed reaction. Thus the observed rate of oxidation in the presence of $\mathrm{Pd}(\mathrm{II})$ catalyst justifies the need of a catalyst for a facile oxidation of the TA by BAB in alkaline medium. The activation parameters evaluated for the catalyzed and uncatalyzed reactions explain the catalytic effect on the reaction. The catalyst Pd(II) forms a complex (III) with the oxidizing species, which increases the oxidizing property of the oxidant and makes the oxidation reaction facile. Further, the catalyst Pd(II) favourably modifies the reaction path by lowering the energy of activation (Table 4 ).

Moelwyn-Hughes [31] pointed out that the catalyzed and uncatalyzed reactions proceed parallely through equation:

$k_{1}=k_{0}+K_{C}[\text { catalyst }]^{X}$

Here $k_{1}$ is the observed pseudo first-order rate constant obtained in the presence of $\mathrm{Pd}(\mathrm{II})$ catalyst, $k_{o}$ is that for the uncatalyzed reaction, $K_{C}$ is the catalytic constant and $\mathrm{x}$ is the order of the reaction with respect to $\mathrm{Pd}(\mathrm{II})$ and is found to be unity in the present study. Hence in the present case, the value of $K_{C}$ was calculated using the equation:

$K_{C}=\frac{k_{1}-k_{o}}{\left[\mathrm{Pd}^{\mathrm{II}}\right]}$

The values of $K_{C}$ have been evaluated at different temperatures $(293-313 \mathrm{~K})$ and $K_{C}$ was found to vary with temperature. Further, a plot of $\log K_{C}$ versus $1 / T$ was linear $(r=0.9896)$ and the values of energy of activation and other thermodynamic parameters for the catalyst were evaluated and tabulated in Table 4. Furthermore, a plot of $k^{\prime}$ versus [Pd(II)] at $303 \mathrm{~K}$ was found to be linear $(r=0.9925)$ with an intercept. The ordinate intercept is the rate constant for the uncatalyzed reaction $\left(k_{0}\right)$ and it signifies that both catalyzed and uncatalyzed pathways proceed simultaneously. At $303 \mathrm{~K}$, the value of $k_{o}$ was found to be $1.00 \times 10^{-4} \mathrm{~s}^{-1}$, which is in concord with that obtained in the absence of $\operatorname{Pd}(\mathrm{II})$ catalyst $\left(k_{0}=0.79 \times 10^{-4} \mathrm{~s}^{-1}\right)$ (Table 4). This clearly establishes the above relationship.

Under comparable set of experimental conditions, the TA-BAB oxidation reaction rate is about 10 -fold faster in acid medium com- pared to alkaline medium. This is confirmed by the magnitudes of activation energies (Tables 2 and 4 ). The different oxidizing species of $\mathrm{BAB}$ involved in two media may be responsible for the difference in reactivity. This fact makes us to conclude that the conjugate acid, $\mathrm{PhSO}_{2} \mathrm{NHBr}$ is a more efficient reactive species than the anion, $\mathrm{PhSO}_{2} \mathrm{~N}^{-} \mathrm{Br}$, in the oxidation of TA by BAB.

\section{Conclusions}

It is concluded that the stoichiometry and oxidation products of TA by BAB in acid and alkaline media are the same, but their kinetic characteristics are different. Activation parameters have been computed. Reactions of TA with BAB are 10 -fold faster in acid medium in comparison with alkaline medium. However, oxidation of TA with $\mathrm{BAB}$ in alkaline medium will become facile in the presence of a micro quantity of $\mathrm{Pd}(\mathrm{II})$ catalyst and reaction rates showed that $\mathrm{Pd}(\mathrm{II})$ catalyzed reactions are 6-fold faster than uncatalyzed reactions. This justifies the need of $\operatorname{Pd}(\mathrm{II})$ catalyst in the facile oxidation of TA-BAB redox system in alkaline medium. The obtained kinetic data have been explained by elegant mechanisms and the relevant rate laws.

\section{Acknowledgements}

One of the authors (AS) thanks the Principal and Management of M.E.S. College, Bangalore, for their encouragement. We thank Prof. M.A. Pasha for helpful discussions.

\section{References}

[1] M.M. Campbell, G. Johnson, Chem. Rev. 78 (1978) 65-79.

[2] K.K. Banerji, B. Jayaram, D.S. Mahadevappa, J. Sci. Ind. Res. 46 (1987) 6576.

[3] G. Agnihotri, Synlett 18 (2005) 2857-2858.

[4] E. Kolvari, A. Ghorbani-Choghamarani, P. Salehi, F. Shirini, M.A. Zolfigol, J. Iran. Chem. Soc. 4 (2007) 126-174.

[5] S.P. Meenakshisundaram, R. Sockalingam, J. Mol. Catal. A: Chem. 162 (2000) 269-276.

[6] K.N. Vinod, Puttaswamy, K.N.N. Gowda, J. Mol. Catal. A: Chem. 298 (2009) 60-68.

[7] Puttaswamy, T.M. Anuradha, R. Ramachandrappa, N.M.M. Gowda, Int. J. Chem. Kinet. 32 (2000) 221-230.

[8] S. Ananda, M.G. Ramananda, N.M.M. Gowda, Synth. React. Inorg. Met. Org. Chem. 31 (2001) 1631-1645.

[9] Puttaswamy, R.V. Jagadeesh, Int. J. Chem. Kinet. 38 (2006) 48-56.

[10] D. Ogston, Antifibrinolytic Drugs, 2nd edn., Wiley, New York, 1985, pp. 249-280.

[11] R. Vardanyan, V.J. Hruby, Synthesis of Essential Drugs, 1st edn., ElsevierScience, 2006.

[12] C.J. Dunn, K.L. Goa, Drugs 57 (1999) 1005-1032.

[13] C. Duangrat, K. Wongsri, Y. Pongpaibul, Int. J. Cosmet. 30 (2008) 219227.

[14] W.P. Griffith, The Chemistry of Rarer Platinum Metals, Interscience, New York, 1967, p. 141.

[15] Y. Rajeshwar Rao, M.K. Reddy, Orient. J. Chem. 14 (1998) 13-17.

[16] M.S. Ahmed, D.S. Mahadevappa, Talanta 26 (1979) 590-592.

[17] K.J. Laidler, Reaction Kinetics, 2nd edn., Tata MC-Graw Hill, New Delhi, 1995

[18] F.F. Hardy, J.P. Johnston, J. Chem. Soc. Perkin. Trans. II (1973) 742-746.

[19] J.C. Morris, J.A. Salazar, M.A. Wineman, J. Am. Chem. Soc. 70 (1948) 2036-2041.

[20] E. Bishop, V.J. Jennings, Talanta 1 (1958) 197-212.

[21] B.G. Pryde, F.G. Soper, J. Chem. Soc. (1962) 1582-1588.

[22] T. Higuchi, K. Ikeda, A. Hussain, J. Chem. Soc. B (1962) 546-549.

[23] A. Shukla, S. Gupta, S.K. Upadyay, Int. J. Chem. Kinet. 23 (1991) 279-288.

[24] W.K. Wan, K. Zaw, P.M. Henry, Organometallics 7 (1988) 1677-1683.

[25] F.A. Cotton, G. Wilkinson, C.A. Murillo, M. Bochmann, Advance Inorganic Chemistry, 6th edn., John-Wiley and Sons Inc., New York, 1999, 1109.

[26] S.S. Narayanan, V.R.S. Rao, Rad. Chem. Acta 32 (1983) 211-212.

[27] M. Subhashini, N. Subramanian, V.R.S. Rao, Talanta 32 (1985) 1082-1083.

[28] G. Helfferich, Kinetics of Multistep Reactions, 2nd edn., Elseivier, Amsterdam, 2004.

[29] C.J. Collins, N.S. Bowman, Isotope Effects in Chemical Reactions, Van-Nostrand, Reinhold, New York, 1970, p. 267.

[30] A. Kohen, H.H. Limbach, Solvent Effects in Chemistry and Biology, CRC Press, Florida, 2006, p. 827.

[31] E.A. Moelwyn-Hughes, The Kinetics of Reaction in Solutions, Oxford University Press, London, 1947, pp. 297-299. 